\title{
Tessituras de Avaliação Formativa: um estudo de práticas docentes em construção
}

\author{
SUZANA DOS SANTOS GOMES \\ Mestre em Educação pela Faculdade de Educação da Universidade Federal de \\ Minas Gerais. Professora nos Cursos de Graduação da PUC/MG \\ suzanasg@terra.com.br
}

\begin{abstract}
Resumo
Este trabalho tem por objetivo analisar a prática docente e os processos de avaliação escolar construídos pelos professores, tendo em vista a implementação da avaliação formativa. Para tanto, definiu-se como locus da pesquisa duas escolas de ensino fundamental, de $3^{\circ}$ ciclo de formação da Rede Municipal de Ensino de Belo Horizonte. Essas escolas, desde 1996, assumiram o Projeto Político-Pedagógico Escola Plural, que se fundamenta numa política democrática inclusiva. A abordagem metodológica adotada caracteriza-se pelo estudo de caso, envolvendo observação participante, entrevistas semi-estruturadas, questionários, análise de documentos e realização de grupo focal. A conclusão do trabalho identificou novas práticas de avaliação de princípios formativos em processo de construção e ressaltou a formação, no cotidiano da escola, como espaço-tempo favorável ao trabalho coletivo, ao exercício da reflexão crítica da e sobre a prática docente de avaliação numa perspectiva de transformação da escola, tornando-a mais inclusiva.
\end{abstract}

Palavras-chaves: ensino-aprendizagem, avaliação escolar, formação de professores, Escola Plural

\section{Resúmen}

Este trabajo trata de hacer un análisis de la práctica docente y los procesos de evaluación escolar construídos por los maestros, teniendo en cuenta la implementación de la evaluación formativa. Para ello, dos escuelas de Enseñanza Fundamental del 3er. Ciclo de Formación de la red de enseñanza pública de la ciudad de Belo Horizonte fueron designadas como locus de investigación. Desde 1996 esas escuelas asumieron el Proyecto Político-pedagógico de la Escuela Plural, fundada en una política democrática inclusiva. La metodologia adoptada se caracteriza por el estudio de casos, através de una observación participativa, entrevistas semi estructuradas, encuestas, análisis de documentos y realización de grupo focal. La conclusión del trabajo pudo identificar nuevas prácticas de evaluación de principios formativos en proceso de construcción y destacó la formación, en la rutina cotidiana escolar, como espacio-tiempo favorable para el trabajo colectivo, el ejercicio de la reflexión crítica de la y sobre la práctica docente de evaluación, desde una prespectiva de transformación de la escuela, volviéndola más inclusiva.

Palabras-clave: enseñanza-aprendizado, evaluación escolar, formación de maestros, Escuela Plural. 


\begin{abstract}
The main goal of this paper is to examine the teaching practice and school evaluation processes designed by teachers, focusing on the implementation of formative evaluation. For that purpose, two public schools from the $3^{\text {rd }}$ cycle elementary education in the Municipal School System of Belo Horizonte have been defined as the locus of research. Since 1996, these schools have put into practice the Plural School Political-Pedagogical Project, which is based on na inclusive democratic policy. The methodological approach adopted is based on a careful case study, involving engaged observation, semi-structured interviews, questionnaires, analysis of documents and the implementation of "focus groups". The conclusion of this work has identified new practices of formative principles in the construction process and stressed formation as conducive to a favourable space-time collective effort in the day-to-day school environment, and also as a critical reflection on teachers' evaluation practice aiming at a more inclusive process of school transformation.

Key words: teaching-learning, school evaluation, teacher formation, Plural School.
\end{abstract}




\section{INTRODUÇÃO}

Este trabalho tem por objeto de estudo a avaliação escolar em seu processo de construção formativa. Originou-se do interesse pela pesquisa da prática docente e da possibilidade de implementar propostas de avaliação como processo que abrange a organização escolar como um todo.

Trata-se de um estudo de caso, orientado por uma perspectiva qualitativa, tendo como foco as práticas docentes de avaliação formativa vivenciadas no dia-a-dia do processo ensino-aprendizagem por professores e alunos do $3^{\circ}$ ciclo $^{1}$ do ensino fundamental em escolas públicas de Belo Horizonte que, desde 1996, assumiram o Projeto Político Pedagógico Escola Plural. O trabalho de campo foi desenvolvido de maio a outubro de 2002, e os procedimentos utilizados para a coleta de dados foram a observação participante, entrevistas semi-estruturadas, questionários, análise documental e grupo focal. Do conjunto de docentes do $3^{\mathrm{a}}$ ciclo, foram investigados, de forma proximal, professores de várias áreas do conhecimento, envolvidos no Projeto Intervenção ${ }^{2}$ Tal escolha se deu por se tratar de uma proposta pedagógica assumida pelos professores com o propósito de interferir positivamente nos alunos para garantir aprendizagem efetiva.

Posto isso, pretendemos investigar, com essa proposta, o significado real dos processos de aprendizagem escolares. Diversas experiências têm sido vividas pelas escolas municipais que aderiram à proposta plural, buscando (re)significar sua prática, desencadeando um processo de construção de uma nova lógica educativa, pautada nos conteúdos de suas disciplinas, no tempo e nas necessidades de formação de seus alunos. Nesse sentido Arroyo (1995, p.43) salienta o papel "crítico e ético do professor que permite definir o que fazer; onde intervir; que dimensões, saberes, valores, competências formar nos diversos coletivos dos educandos". A construção do $3^{\circ}$ ciclo significou redefinir a função social

1 A Escola Plural propõe a organização da Educação Básica (ensino fundamental) em três Ciclos de Formação: Primeiro Ciclo Básico - período característico da infância, abarcando os alunos na faixa de 6-7, 7-8, 8-9 anos de idade; Segundo Ciclo Básico - período característico da pré-adolescência, abarcando os alunos de 9-10, 10-11,11-12 anos; Terceiro Ciclo Básico - período característico da adolescência, abarcando os alunos de 12-13, 13-14 e 14-15 anos.

2 Projeto Intervenção visa atender aos alunos que se encontram em diversos níveis de aprendizagem em uma mesma turma. À época da pesquisa, ocorria duas vezes por semana (último horário, às $3^{\mathrm{a}}$ e $5^{\mathrm{a}}$ feiras). Os alunos eram (re)enturmados dentro do ciclo, constituindo agrupamentos diversificados, aproximando-se os níveis de conhecimentos e habilidades específicas. 
desse tempo escolar, tratando o adolescente como sujeito sociocultural no seu tempo específico de formação. Permanece, porém, o desafio: concretizar práticas de avaliação para um processo de formação contínua.

\section{AVALIAÇÃO FORMATIVA: UM PROCESSO DE INTERVENÇÃO DIDÁTICA}

A redefinição do processo de avaliação dá continuidade a uma dinâmica estabelecida a partir do modelo qualitativo e agrupa propostas que, embora distintas, desencadeiam práticas com conseqüências semelhantes. Essas propostas rompem com a avaliação quantitativa, e são construídas com base em um discurso crítico à concepção de avaliação como quantificação dos resultados. Além disso, compartilham da idéia de que os sujeitos escolares são sujeitos históricos e sociais.

Tal análise mostra a necessidade de reconstrução do processo de avaliação como parte de um movimento articulado com o desenvolvimento de uma prática pedagógica comprometida com a inclusão, com a pluralidade, com o respeito às diferenças, com a construção coletiva. Um movimento direcionado pela concepção de escola como território múltiplo, marcado pela diversidade de cultura e vozes. Essa transformação requer uma redefinição paradigmática do conceito de avaliação (Barriga, 1992).

Nesse ponto é importante destacar que será a partir da segunda metade da década de 80 que novas perspectivas de análise abrem caminho para o conhecimento da escola e das suas práticas. Daí, uma nova concepção de avaliação formativa, por exemplo, se configura recebendo diferentes denominações: alternativa emergente por Lüdke (1992), emancipatória por Saul (1994) e crítica por Luckesi (1995). Já Wachowicz (2001), em sua abordagem sobre avaliação, discute a avaliação dialética e propõe uma mudança da avaliação de resultados para uma avaliação de processo, indicando a possibilidade de realizá-la, na prática, pela descrição e não pela prescrição da aprendizagem.

Nesse sentido, Dalben diz:

"Este novo conceito de avaliação defende uma nova concepção de trabalho pedagógico, alterando a perspectiva transmissiva de processo de ensino. Proclama uma interação permanente: professor $x$ aluno $x$ conhecimento e, neste contexto, o sentido da avaliação direciona-se para um processo de investigação contínua e dinâmica da relação pedagógica como um todo." (1999, p.78)

De acordo com essa nova concepção docente, o professor acompanha todo o processo de avaliação, coleta dados, informações sobre o 
aluno e, cuidadosamente, registra suas necessidades e possibilidades. Nessa perspectiva, o processo de ensino torna-se um desafio para o professor, que deverá estar atento à investigação das questões que merecem maior investimento pedagógico e, conseqüentemente, alteração nos encaminhamentos didáticos.

Além disso, pretendemos entender a avaliação formativa como atividade contínua, progressiva, sistemática, flexível, orientadora da atividade educativa e personalizada, ao respeitar o ritmo individual de desenvolvimento de cada aluno. A propósito, Allal, Cardinet, Perrenoud (1986), André (2001), Perrenoud (1999, 2001), Dalben (2000), Lüdke (1992), Villas Boas (2001) e outros pesquisadores oferecem contribuições significativas no que se refere ao desafio de tornar a avaliação um processo formativo, construído ao longo do processo ensino-aprendizagem.

Assim compreendida, a avaliação formativa consiste em uma prática educativa contextualizada, flexível, interativa, presente ao longo do curso, de maneira contínua e dialógica (Freire,1975). Dessa forma, o aperfeiçoamento da prática educativa deve ser o objetivo básico de todo educador. E entende-se por aperfeiçoamento o meio pelo qual todos os alunos consigam o maior grau de competências, conforme suas possibilidades reais.

Novos conhecimentos didáticos têm subsidiado o professor no trabalho de organizar situações-problema ajustadas às diferenças e às possibilidades dos alunos, e de desenvolver um clima de cooperação em sala de aula que estimule um apoio pedagógico integrado para os alunos em seus diversos níveis de aprendizagem.

Afinal, fazendo parte da reflexão sobre a eficácia do ensino, a avaliação formativa deve ser pensada no âmbito da didática. A didática fala, então, a linguagem das situações de comunicação. No dizer de Martins (1998), trata-se de um compromisso baseado na reconstrução de novas práticas: olhar crítico sobre a realidade/ação sobre a realidade/pensamento. Trata-se de redescobrir regulações adaptadas às novas exigências e desafios da docência.

Sob esta perspectiva, conceber a didática como dispositivo de regulação é romper com a distinção clássica entre o tempo do ensino, no sentido amplo, e o tempo da regulação. Assim, a concepção de didática que pretendemos defender refere-se a um dispositivo que favorece uma regulação contínua das aprendizagens. Martins (1998) salienta que o trabalho com a avaliação mais democrática perpassa o campo da didática, da relação professor/aluno e da organização pedagógica da escola. 


\section{CONCEPÇÕES DOS PROFESSORES SOBRE A AVALIAÇÃO ESCOLAR}

Nesse tópico são apresentados os dados obtidos nas entrevistas realizadas com os professores da Escola Municipal Ângela Martins EMAM $^{3}$, buscando identificar as principais questões pedagógicas apontadas pelos docentes. Conforme já foi dito, os sujeitos selecionados para a pesquisa foram os professores que atuam no Projeto Intervenção. Procuramos garantir a presença de professores do $1^{\circ}, 2^{\circ}$ e $3^{\circ}$ ano do $3^{\circ}$ ciclo, com ênfase em um grupo diversificado, que permitisse traçar um retrato preliminar da prática docente de avaliação.

Na EMAM, o grupo de docentes do $3^{\circ}$ ciclo da manhã compõe-se de nove professores e uma coordenadora pedagógica. Dos dez docentes pesquisados, todos são graduados e dois estão concluindo pós-graduação latu sensu. Isso comprova que a escola tem um corpo docente qualificado o que, sem dúvida, lhe traz ganhos já que a formação inicial é fator importante na formação docente.

Indagados sobre a prática docente de avaliação, os professores pesquisados revelaram: as principais formas de ensino adotadas; os principais problemas do dia-a-dia e os resultados positivos dessa prática; as formas de avaliação utilizadas. Apontaram, também, ações/estratégias desenvolvidas com alunos de diferentes níveis no campo da aprendizagem.

Sobre as principais formas de ensino adotadas pelos docentes, de acordo com os dados coletados, são explorados o trabalho individual, a exposição dialogal seguida de trabalhos em dupla e em grupo. Os dados atestam, ainda, que os principais problemas do cotidiano da sala de aula são: as diferenças no nível de aprendizagem, a falta de compromisso dos alunos com as tarefas de casa e a ausência da família.

Quanto aos resultados positivos obtidos dessa prática de ensino, os professores destacaram o trabalho com projetos, a prática do diálogo e de conscientização dos alunos e a ação democrática implementada na escola. De acordo com os dados, são altos os índices do trabalho coletivo, relações interpessoais e conhecimento do aluno.

Segundo as entrevistas, as principais práticas de avaliação adotadas pelos professores concentram-se nas formas: observação em sala de aula, exercícios e registro no caderno, participação, e compromisso com os deveres escolares. Pude observar que os docentes estão diversificando as formas de avaliação. As provas são realizadas, mas não são aplicadas por todos como única estratégia de avaliação ou a mais importante.

3 O nome da escola e dos professores citados no artigo são fictícios. 
Verificamos que um número significativo de professores aplica avaliações em dupla e em grupos. Também alguns adotam a prática da autoavaliação.

Por sua vez, em seu Projeto Político Pedagógico, os docentes chegaram a definir uma linha para a avaliação escolar. Segundo eles, devese considerar como eixo de avaliação o processo percorrido pelo aluno na construção do conhecimento e não somente o produto adquirido. Ela deve ser, portanto, contínua, dinâmica e investigativa. A propósito, eis alguns depoimentos ${ }^{4}$ de professores sobre a avaliação:

"Eu sou contra a cultura da nota, da reprovação. Não foi fácil para nós romper com essa lógica e até hoje somos punidos pelos pais e pela comunidade pela nossa proposta alternativa. Queremos que o nosso aluno tenha uma outra relação com o conhecimento." (James, Geografia, $3^{\circ}$ ciclo, EMAM)

E, ainda:

"Já há algum tempo nós estamos trabalhando muito, tentando descobrir e aprender formas de lidar com esse aluno que apresenta necessidades de acompanhamento em muitas dimensões. O estudo de caso que fizemos ajudou a entender a história de vida desse aluno. A avaliação mudou. É processual. A intervenção tem sido uma forma de acompanhar esse aluno. Mas ainda temos muito que avançar." (Sônia, Ciências, $3^{\circ}$ ciclo, EMAM)

Mas observamos que os docentes têm consciência da necessidade de mudar o foco da avaliação tornando-a mais formativa. Nesse caso, percebemos que não só o processo de avaliação do educando é muito importante como também o registro desse processo, pois, assim, é possível obter o retrato do desenvolvimento do aluno em relação a si mesmo e aos objetivos propostos. Aliás, em sua prática, os professores optaram pela elaboração do Caderno da Turma e conforme já foi dito, nele realizam registros do desempenho dos alunos.

Em seus relatos, verificamos também que concordam com o caráter formativo dos instrumentos de avaliação, devendo-se evitar que a punição prevaleça. Acreditam que esses instrumentos servem para organizar o conhecimento, para diagnosticar o que se sabe e o que ainda não se sabe. Nesse sentido, propiciam, também, momentos de aprendizagem, uma vez que provoca o desenvolvimento do educando e reorienta a prática do professor.

4 Todas as transcrições de falas de professores e alunos neste trabalho estão apresentadas na íntegra. 
Como se vê, um dos elementos fundamentais da concepção de educação e escola trazido pelo Programa Escola Plural é a avaliação. Nessa nova concepção, avaliar não significa classificar, aprovar ou reprovar. Implica, isto sim, incidir sobre aspectos globais do processo, inserindo tanto questões ligadas ao processo ensino-aprendizagem quanto as que se referem à intervenção do professor no projeto curricular da escola, na organização do trabalho escolar, na função socializadora e cultural, na formação de identidades, de valores, da ética, enfim, no seu projeto pedagógico.

No caso da EMAM, é importante destacar que o processo de avaliação não ocorre de forma pontual, localizada e/ou parcelarizada, mas se dá em todos os espaços da nova organização do trabalho na perspectiva plural. Avaliação, portanto, é entendida como um processo permanente, com caráter diagnóstico e, por isso, deve apontar soluções para os problemas detectados na aprendizagem

Ilustram esse processo, os comentários desses professores do $3^{\circ}$ ciclo:

"Avalio os meus alunos através de avaliação diagnóstica, observação em sala de aula do trabalho individual, em dupla ou pequenos grupos. Aplico também provas no final da etapa e crio espaço para a auto-avaliação do aluno." (Gildo, Matemática, $3^{\circ}$ ciclo, EMAM)

E ainda:

“Na avaliação é fundamental acompanhar o cotidiano da sala de aula, observar como os alunos se relacionam, cumprem sua tarefa escolar. Costumo diversificar as avaliações. Aplico prova individual ou em dupla e para os trabalhos em grupos proponho a auto-avaliação." (Narla, História, $3^{\circ}$ ciclo, EMAM)

Ademais, os docentes acreditam numa avaliação de caráter formador, diagnóstico e qualitativo. O processo de avaliação é subsidiado por instrumentos diversos que são utilizados cotidianamente com o objetivo de diagnosticar os avanços e as dificuldades dos alunos, tendo em vista o processo de ensino-aprendizagem adotado, com relação às várias dimensões de formação (cognitiva, social, afetiva). Porém, consideram ainda como principal avanço da Escola Plural a prática coletiva da avaliação. Essa prática garante que os princípios e intenções definidos coletivamente sejam respeitados; garante, também, a pluralidade de análises sobre o processo educativo.

No que diz respeito às formas e instrumentos de avaliação adotados pela EMAM, participamos de reuniões de professores do $3^{\circ}$ ciclo, 
atividades em sala de aula e conselhos de classe. Também examinamos fichas e instrumentos construídos pela escola. As atividades relativas ao processo de avaliação culminaram com a socialização dos resultados obtidos no final da primeira etapa de 2002, nas reuniões de Conselhos de Classe 5 .

Observamos, ainda, que, nessa escola, o trabalho coletivo tem se apresentado como um caminho que facilita a construção de práticas de avaliação. Esse trabalho se dá na interação de professores e alunos com toda a comunidade escolar. Tal prática busca-se consolidar no cotidiano da escola.

Dessa forma, torna-se essencial assegurar espaços coletivos de construção de práticas docentes de avaliação, espaços escolares construídos pela presença e ação significativa dos sujeitos que constituem a instituição escolar. Partindo desse princípio, os docentes buscam, no cotidiano, propiciar vivências coletivas em que valores sejam manifestos; promover interações em espaços diversificados; utilizar os diferentes recursos de comunicação e pesquisa; interagir com a multiplicidade de processos de produção exteriores à escola.

\section{GRUPO FOCAL: AVALIAÇÃO DOS ALUNOS SOBRE O PROJETO INTERVENÇÃO}

Apresentamos, nesta parte, a visão e a voz dos alunos participantes do Projeto Intervenção a fim de captar como eles percebem e avaliam o trabalho docente, que aspectos desse trabalho consideram importantes, quais são os principais valores, sentimentos e expectativas deles com relação à escola que está em fase de formação. Para tanto, foi escolhida a técnica do grupo focal ${ }^{6}$.

O trabalho com o grupo focal não procura o consenso, mas, em especial, a emergência das opiniões, preocupações, prioridades e contradições entre os atores. Os indivíduos que participam de um grupo focal devem ser representativos da população interessada. Essa técnica grupal possibilita a estruturação de aspectos dialógicos entre os membros,

5 Participam dos Conselhos de Classe: alunos, pais e/ou responsáveis pelos alunos, professores da turma, coordenadores de ciclo e direção. Nesse espaço coletivo os professores apresentaram aos pais e alunos os registros de avaliação realizados durante a etapa.

6 O grupo focal é uma técnica de investigação qualitativa utilizada nas Ciências Sociais para buscar uma resposta aos porquês e como dos comportamentos sociais. É uma fonte de informação útil no entendimento de atitudes, crenças e valores de um grupo ou de uma comunidade. (Krieger, Casey, 1999; Dalben, 2000). 
o confronto de posturas, a argumentação, a réplica, que são importantes para a interpretação das diversas realidades vividas e sentidas.

Dessa forma, utilizamos para seleção dos alunos participantes do grupo focal, os seguintes critérios: três alunos foram indicados pelos professores no conselho de classe ${ }^{7}$, os outros cinco foram selecionados a partir das minhas observações em sala de aula. Na medida do possível, procuramos envolver o representante de turma por ter uma função de representatividade junto à escola. Escolhemos também alunos que se sobressaíram nas relações interpessoais em sala de aula. Isso posto, eis o resumo das principais informações coletadas durante a realização do grupo focal.

A experiência dessa técnica na EMAM foi introduzida por uma música. Observamos que os alunos demonstraram grande interesse na dinâmica, cantaram a música e refletiram sobre ela. A impressão geral foi que se sentiram valorizados por terem sido escolhidos. Alguns se revelaram mais expressivos ao verbalizar suas opiniões, outros apenas concordaram com os colegas.

Conversaram sobre os alunos que não levam as aulas a sério, atrapalham, quando muitos querem aprender. Nesse caso, de acordo com eles, desinteressados prejudicam os interessados. $\mathrm{E}$ a respeito das excursões promovidas pelos professores, na opinião deles, ajudam a aprender de forma diversificada.

Quanto à classificação de alunos em melhor/pior, afirmaram que os que não foram bem nas atividades sentem-se constrangidos diante do grupo. Defenderam maior rigor dos professores com os alunos que não querem estudar. Lembraram que as reuniões deveriam ser realizadas à noite para que os pais pudessem participar. Destacaram também a importância dos diversos projetos escolares.

Questionados sobre o Projeto Intervenção, os alunos afirmaram que é bom, parecido com uma aula particular. E, assim, disseram:

"É legal também porque aprendemos muita coisa que antes achávamos difícil. Foi uma forma que os professores acharam para nos ajudar no ensino. Dá para fazer vários amigos e aprender mais coisas que não aprendemos na sala regular ou achamos difícil." (STM, $1^{\circ}$ ano, $3^{\circ}$ ciclo)

\footnotetext{
7 No conselho de classe contamos com a participação dos professores na indicação dos alunos. A expectativa era ter um grupo bem heterogêneo. Definimos então: um aluno de bom desempenho e dois em estágio de intervenção.
} 
"Eu fui acelerada do $1^{\circ}$ ano para o $3^{\circ}$ ano e estou muito bem. Vim da EEEP, acho a Escola Plural boa. Quem faz ela ser ruim é o aluno que não estuda." (PHS, $3^{\circ}$ ano, $3^{\circ}$ ciclo)

"Tem alguns alunos que sabem que passam e não estão estudando. Não tem como o professor avançar se o aluno não estuda. Para esses alunos tirar a bomba foi ruim. Precisam de mais incentivo para estudar. Eu estudo porque quero." (PFR, $1^{\circ}$ ano, $3^{\circ}$ ciclo)

Apontaram, também, a necessidade de se rever o horário da Intervenção, que é no final da manhã, quando eles e os professores estão cansados. Quanto à organização dos grupos, lembraram que precisa ser revista periodicamente a fim de se avaliar quem precisa de mais acompanhamento e em que direção, e quem foi bem-sucedido. Já os monitores lembraram que a intervenção possibilita maior entrosamento no $3^{\circ}$ ciclo: existe apoio, interesse em ajudar quem precisa e colaboração dos professores. Salientaram a necessidade de maior empenho nos estudos por parte dos alunos, além da freqüência às aulas. Nas palavras deles:

"No começo odiava, achava desorganizado, não queria fazer. Com o passar do tempo, os professores se organizaram e comecei a me interessar. É um projeto legal, os alunos conseguem aprender." (Monitora MTS, $3^{\circ}$ ano, $3^{\circ}$ ciclo)

"Minha experiência como monitora tem sido ótima. No começo os alunos não gostavam muito da gente. Com o tempo ficamos amigos. E eles gostam que a gente passe nas carteiras ensinando. A gente aprende muito com eles também." (Monitora $\mathrm{ANR}, 3^{\circ}$ ano, $3^{\circ}$ ciclo)

Foi possível perceber nas discussões o quanto a escola é importante na vida desses adolescentes. Os tímidos também foram capazes de expressar seus sentimentos e impressões com relação ao que presenciam na escola: apontaram os aspectos positivos e negativos da instituição. Outros, ainda, concordaram com os colegas com um gesto ou breve expressão.

Concluindo, o uso da técnica do grupo focal possibilitou-nos verificar que, no Projeto Intervenção, os professores oferecem estratégias pedagógicas diferenciadas. Com isso, desenvolvem nos alunos as dimensões: cognitiva, relacional, social e afetiva. Investem em atividades e situações de aprendizagem significativas e mobilizadoras, levando em conta as diferenças pessoais e culturais existentes na sala de aula. 


\section{TRABALHO COLETIVO E FORMAÇÃO CONTINUADA DOS PROFESSORES}

Documentos pesquisados na escola em estudo fazem referência à formação docente, defendendo a sua realização dentro da escola, prioritariamente, com a participação de todos os professores. Defendem também investimento na formação em serviço a partir da realidade do trabalho: desafios, limites e possibilidades.

Analisando os documentos, verificamos que estão definidas algumas intenções para a construção do projeto de formação. Para tal, os docentes apontam a construção de competências. No caso, competência é entendida como capacidade de agir eficazmente em um determinado tipo de situação, apoiada em conhecimentos, mas sem limitar-se a eles, na busca e análise do contexto da prática, explicitando as intenções educativas, as representações da realidade vivida nos processos de ensino-aprendizagem, e construindo um projeto de formação baseado na autonomia.

Propõem, ainda, compromisso com a postura de pesquisadores. No ponto de vista deles, ela se manifesta quando se questiona o próprio pensamento nas relações de ensino, considerando que o pensar é uma maneira que os professores têm para responder às questões da própria identidade. Significa, com base em uma ação política, lembrar quem somos, onde estamos e o que queremos. Nesse sentido, torna-se importante, a prática do registro, o fortalecimento crítico do fazer e o desenvolvimento de metodologias diferenciadas.

Coerentes com essa proposta, mudanças na prática docente e de avaliação vêm acompanhadas, hoje em dia, do conhecimento de programa de formação continuada para os professores. É reconhecida a noção de que o processo de interação, mediado pelo conhecimento, modifica o educando e o educador. A prática vivida no cotidiano escolar aflora problemas concretos que são compartilhados no coletivo, procurando ser solucionados. A necessidade de discussão aprofundada sobre os aspectos da aprendizagem, a relação professor-aluno e o diálogo com o conhecimento é premente.

Sobre a formação continuada, vários autores apresentam propostas, mas constitui ainda um campo em desenvolvimento. Reconhecendo a importância da formação contínua, muitas escolas têm criado espaços para envolver os professores na construção de projetos formativos a fim de buscarem juntos, novas competências para ensinar com base na percepção e na vivência dos próprios docentes.

Também, a nova modalidade de organização em ciclos exige mudança na concepção de ensino, aprendizagem e avaliação e, 
conseqüentemente, exige melhor preparação dos professores. Hoje, apostase na capacidade de os professores crescerem no trabalho de intervenção junto aos alunos. Diante desse grande desafio, a realidade dessa prática exige: ritmos diferenciados, experiências de vida, conhecimentos diversos.

\section{RESULTADOS}

Os dados desta pesquisa demonstram que aprender e ensinar é um processo que vai se consolidando no exercício profissional. Portanto, a prática pedagógica possibilita a reconstrução da função docente. Assim, à medida que o professor vai efetivando a articulação entre o conhecimento teórico-acadêmico, dados do contexto escolar e da prática docente de avaliação, por meio da reflexão-ação, cada vez mais interferem na aprendizagem dos alunos.

Nesse sentido, verificamos pelos dados apontados pela pesquisa que o grupo de professores implementou a avaliação formativa e desenvolveu um projeto de atendimento às diferenças dos alunos, cujo suporte era o processo de formação em serviço, construído por eles. E esse processo foi ganhando sentido à medida que o trabalho coletivo foi se constituindo como expressão de uma colaboração reflexiva entre pares.

Por fim, ressaltamos que, ao orientar o olhar para as pedagogias diferenciadas como propõe Perrenoud (2001), esse processo provoca no aluno e no professor, uma outra construção de sentido. Para o autor, o sentido da prática, dos saberes, das situações de aprendizagens escolares não é algo dado a priori, mas algo construído com base num conjunto de valores e representações e numa situação de interação e reciprocidade.

\section{REFERÊNCIAS BIBLIOGRÁFICAS}

ALLAL, L.; CARDINET, J.; PERRENOUD, P. A Avaliação formativa num ensino diferenciado. Coimbra: Almedina, 1986.

ANDRÉ, Marli. (org.) Pedagogia das diferenças na sala de aula. 2 ed. Campinas: Papirus, 2001.

ARROYO, Miguel Gonzalez. Quando a escola se redefine por dentro. In: Presença Pedagógica, nov./dez. 95, p. 39-49. 
BARRIGA, A. D. (comp.) El examen: textos para su historia y debate. México: UNAM, 1992.

DALBEN, Ângela Imaculada de Freitas. Avaliação escolar e a relação com o conhecimento. Caderno de Educação. APUBH - S. SIND. 1999, p. 74-87.

(org.) Avaliação da implantação do projeto político pedagógico Escola Plural. Belo Horizonte: GAME/FAE/UFMG, 2000.

FREIRE, Paulo. Pedagogia do oprimido. Rio de Janeiro: Paz e Terra, 1975.

LUCKESI, Cipriano. Avaliação da aprendizagem escolar: estudos e proposições. 2ed. São Paulo: Cortez, 1995.

LÜDKE, Menga. Um olhar sociológico sobre a avaliação escolar. Tecnologia Educacional. v.21, n. 108, set/out. 1992.

KRIEGER, R.; CASEY, M. Overview of Focus Groups. In: Focus Groups: a practical guide for applied research. Thousand Oaks, Sagon Publications, 3 rd Edition, Cap. 1, p. 3-37, 1999.

MARTINS, Pura Lucia Oliver. A didática e as contradições da prática. Campinas: Papirus, 1998.

PERRENOUD, Philippe. Avaliação: da excelência à regulação das aprendizagens - entre duas lógicas. Porto Alegre: Artes Médicas Sul,1999.

Pedagogia na escola das diferenças: fragmentos de uma sociologia do fracasso. Trad. Cláudia Schilling. Porto Alegre: Artmed, 2001.

SAUL, A. M. G. Avaliação emancipatória: desafios à teoria e à prática de avaliação e reformulação de currículo. 2 ed. São Paulo: Cortez, 1994.

VILLAS BOAS, Benigna Maria de Freitas. Avaliação formativa: em busca do desenvolvimento do aluno, do professor e da escola. In: VEIGA, I.P.A.; FONSECA, M. (orgs.). As dimensões do projeto político-pedagógico: novos desafios para a escola. Campinas: Papirus, 2001.

WACHOWICZ, Lilian. A dialética da aprendizagem na pedagogia diferenciada. In: CASTANHO, S.; CASTANHO, M.E. O que há de novo na Educação Superior. Campinas: Papirus, 2001, p. 95-129.

Recebido em: outubro 2003 Aprovado para publicação: novembro 2003 
